\title{
Interactive comment on "SoilErosionDB: A global database for surface runoff and soil erosion evaluation" by Jinshi Jian et al.
}

\section{Anonymous Referee \#2}

\section{Received and published: 12 April 2021}

This reviewer totally agreed with Prof. Dr. Karl Auerswald's comments. A global database for surface runoff and soil erosion is very valuable for research community in hydrology and soil erosion. This reviewer was very interested in the database and downloaded SoilErosionDB. However, I worried about its reliability and utility. Soil erosion is a very complex process as it relates various aspects and factors including climate, soil, topography, biology and human activities, and it covers different spatial and temporal scales. The results from different scales can not compare directly, which should be paid more attention to. This reviewer would suggest the authors start from a small topic, such as the collection of observations for the runoff and soil erosion of field plots, which are very important for the development and calibration of soil erosion models. In addition, before the release of the database, strict quality control and analysis 
on the dataset are necessary.

Interactive comment on Earth Syst. Sci. Data Discuss., https://doi.org/10.5194/essd-2020-283, 2020.

Interactive comment 